\title{
Aprendizaje situado,
} una alternativa para responder a los retos educativos de hoy

\section{Luis Gerardo Gómez Márquez.}

a ara realizar acciones en el área de educación es imprescindible conocer la realidad en la que ésta se desarrolla, o habrá de desarrollarse. El aprendizaje situado es aquella metodología que pretende unir la educación con la realidad, ya que permite al estudiante aprehender de esta realidad en su entorno para entender y afirmar sus conocimientos. Por tanto, a partir de esta afirmación, la mayor parte de los planes y programas de estudio suelen estar descontextualizados, pues son realizados en su mayoría por individuos que no conocen las realidades en las que se pretende llevar a cabo su aplicación.

Tomemos como ejemplo el siguiente: un grupo de alumnos de sexto de primaria de una comunidad rural del estado de Jalisco lleva el mismo plan de estudios diseñado por la Secretaría de Educación Pública (SEP), de los alumnos que cursan el sexto año de primaria en la ciudad de Monterrey; el contexto de la primera institución es muy diferente al de la segunda, ambos resultan diametralmente opuestos, por tanto, es poco coherente pretender que exista un aprovechamiento similar en ambas instituciones, y más aún, pretender que sean evaluados a nivel nacional con el mismo instrumento, ENLACE (Evaluación Nacional del Logro Académico en Centros Escolares) (SEP, 2012).

En esta línea, Hendricks (2001) sugiere que los estudiantes deberían enfrentarse con situaciones similares a las de un especialista en su campo de formación, y estima que el aprendizaje situado asume diferentes formas y nombres, directamente vinculados con conceptos como participación periférica legítima, aprendizaje cognitivo (cognitive apprenticeship) o aprendizaje artesanal. Partiendo de esto, se destaca la importancia de la actividad y el contexto para el aprendizaje y se reconoce que el aprendizaje escolar es, ante todo, un proceso de enculturación en el cual los estudiantes se integran gradualmente a una comunidad o cultura de prácticas sociales, mismas que varían de manera considerable de un lugar a otro; por esta razón, resulta necesario ubicar que independientemente del denominativo que se le dé, la educación situada es un proceso que puede representar una alternativa para la mejora de la calidad educativa y para conseguir que se presente dentro de los procesos de enseñanza y aprendizaje una metacognición y una posterior transferencia, ya que esa estrategia debería permitir que se dé sentido y significado a los conocimientos teóricos en favor del constructivismo. 
Los teóricos de la cognición situada (Lev Vygotsky, Leontiev, Luria, Rogoff, Lave, Bereiter, Engeström y Cole) parten de una fuerte crítica a la manera en que la institución escolar intenta promover el aprendizaje, como si se tratara de una programación en serie y se estuviera trabajando con objetos, no con personas, ya que pareciera que no es importante respetar los procesos, ritmos y canales de percepción de cada uno de los alumnos. En particular, cuestionan la forma en que se enseñan aprendizajes declarativos abstractos y descontextualizados, conocimientos inertes, poco útiles y escasamente motivantes, de relevancia social limitada (Díaz Barriga y Hernández, 2002: 125). Es difícil que al alumno le resulte significativo aquello que escapa de su realidad/contexto, puesto que el conocimiento es tratado como si fuese algo ajeno a su mundo, cuando éste debería representar todo lo contrario. Por eso, es tan común en el nivel medio superior escuchar que los alumnos llaman a algunas materias como "de relleno", pues no encuentran el sentido de llevar esas materias si no son aplicables o útiles en su vida cotidiana.

Estamos acostumbrados a escuchar que la educación en nuestro país presenta un rezago evidente; y a pesar de la gran diversidad de evaluaciones, no existe un elemento que pueda decirnos si estamos avanzando o en definitiva estamos estancados en este proceso; en pocas palabras, es difícil saber si la educación está siendo efectiva. De acuerdo con Díaz Barriga (2002: 125), se establece la cognición situada como "un paradigma vinculado al enfoque sociocultural vigotskiano, el cual afirma que el conocimiento es situado, es decir, forma parte y es producto de la actividad, el contexto y la cultura", por tanto, no se puede dejar de tomar en cuenta la relación entre las variables contexto y rendimiento, puesto que debemos entender la educación como un proceso integral, el cual no sólo forme individuos competentes en alguna área determinada o específica, sino que además forme personas conscientes de las necesidades sociales y capaces de analizar y resolver los problemas propios de su entorno.

De esta manera, podemos darnos cuenta de que en los procesos de enseñanza y aprendizaje es de gran importancia el contexto donde se desarrolla la acción, puesto que determinará las necesidades de ese lugar, y así, las necesidades del individuo, ya que también resulta una premisa básica ubicar su papel, con la intención de lograr un aprendizaje significativo y llegar a los objetivos planteados para lograr también una mayor integración de los contenidos, y así realizar mejoras en la comunidad; con esto se quiere aclarar que no se puede ver a la educación (en este caso los planes y programas) como una receta de cocina. Como lo menciona Engeström (citado en Baquero, 2002: 115), una situación educativa, para efectos de su análisis e intervención instruccional, requiere concebirse como un sistema de actividad, cuyos componentes por ponderar incluyen:

1. El sujeto que aprende.

2. Los instrumentos utilizados en la actividad.

3. El objeto que va a apropiarse u objetivo que regula la actividad (saberes y contenidos).

4. Una comunidad de referencia en que la actividad y el sujeto se insertan.

5. Normas o reglas de comportamiento que regulan las relaciones sociales de esa comunidad.

6. Reglas que establecen la división de tareas en la misma actividad.

Con una explicación concreta y puntual, el primero de los incisos nos deja claro quién es el actor más importante en este proceso; de la misma forma, coloca en segundo lugar a los instrumentos, esto debido al papel que juegan como coadyuvantes en los procesos de enseñanza y aprendizaje; en tercer lugar, sitúa los contenidos, pues son la parte que va a apropiarse, acompañados del lugar en el que se desenvuelven los individuos, así como sus normas y reglas, tanto en la regulación de relaciones como en la división de tareas. Con esta aportación es más evidente que la mayoría de quienes se han dedicado a estudiar este paradigma dan un lugar especial y un valor relevante al individuo en proceso y al contexto como variables inseparables, pasando a un plano secundario, aunque no menos importante, a los contenidos, cuya adquisición y aplicación en el contexto habrán de conformar el cierre del ciclo.

El aprendizaje situado tiene como acto primero la realidad, no inicia un tema con la parte teórica, por el contrario, comienza contextualizando un fragmento de la realidad con la intención de hacer que posteriormente los alumnos la relacionen con la teoría. Desde el contexto mismo del aprendizaje situado es importante mencionar que no se trata de una moda -como ha sucedido en otras ocasiones con algunas tendencias en materia educativa-, y que este paradigma basado en la metodología constructivista proporciona los elementos adecuados para favorecer este pro- 
ceso, debido a que proporciona los elementos necesarios y adecuados para poder entender, analizar y modificar el contexto a partir de la construcción de aprendizajes. De acuerdo con Díaz y Hernández (2012: 48), la misma metodología se menciona de manera breve a continuación, ya que da la pauta para la activación de los siguientes procesos:

1. Partir de la realidad.

2. Análisis y reflexión.

3. Resolución en común.

4. Elaboración de un proyecto transversal.

Para el primer aspecto debe partirse de un suceso o acontecimiento que tenga trascendencia dentro de la comunidad y que pueda tener un impacto mayor o menor dentro de ésta, puede seleccionarse un fenómeno micro o macrosocial; respecto al análisis y reflexión, éstos son los procesos de mayor riqueza intelectual y en donde se podrá ver favorecido el constructivismo en el aula, en unión con la tercera fase, la resolución en común, ya que permitirá, de manera grupal, buscar soluciones que permitan solventar problemáticas del contexto, con las que los estudiantes se sientan no sólo identificados, sino incluso involucrados; finalmente, el proyecto representa la evidencia respecto al proceso que se va a seguir para llegar a un acuerdo común en beneficio no sólo de ellos, sino global.

A modo de conclusión, la educación situada representa una alternativa coherente ante las realidades sociales de los diferentes contextos en donde se desarrolla la educación en nuestro país, esto porque proporciona las herramientas necesarias para conseguir que los estudiantes encuentren una aplicación práctica a aquellos conocimientos teóricos adquiridos en el aula, situación que al no presentarse deja de ser significativa para los estudiantes de todos los niveles, puesto que si no saben qué utilidad debe darse a lo que han aprendido sólo lo verán como un conocimiento estéril.

\section{Fuentes de consulta}

Baquero, R. (2002). Del experimento escolar a la experiencia educativa. La transmisión educativa desde una perspectiva psicológica situacional. Perfiles Educativos, 24(97-98).

Díaz Barriga, F. y Hernández, G. (2002). Estrategias docentes para un aprendizaje significativo. Una interpretación constructivista ( $2^{\mathrm{a}}$ ed.). México: McGraw Hill.

Díaz, M. y Hernández, J. (2012). Aprendizaje situado, transformar la realidad educando. México: GrupoGráfico Editorial.

Hendricks, Ch. (2001). Teaching Causal Reasoning Through Cognitive Apprenticeship: What are results from situated learning? The Journal of Educational Research, 94(5).

Secretaría de Educación Pública (SEP) (2012). http://www.enlace.sep.gob.mx/ba/ consultada por última vez el día 30 de enero de 2013.

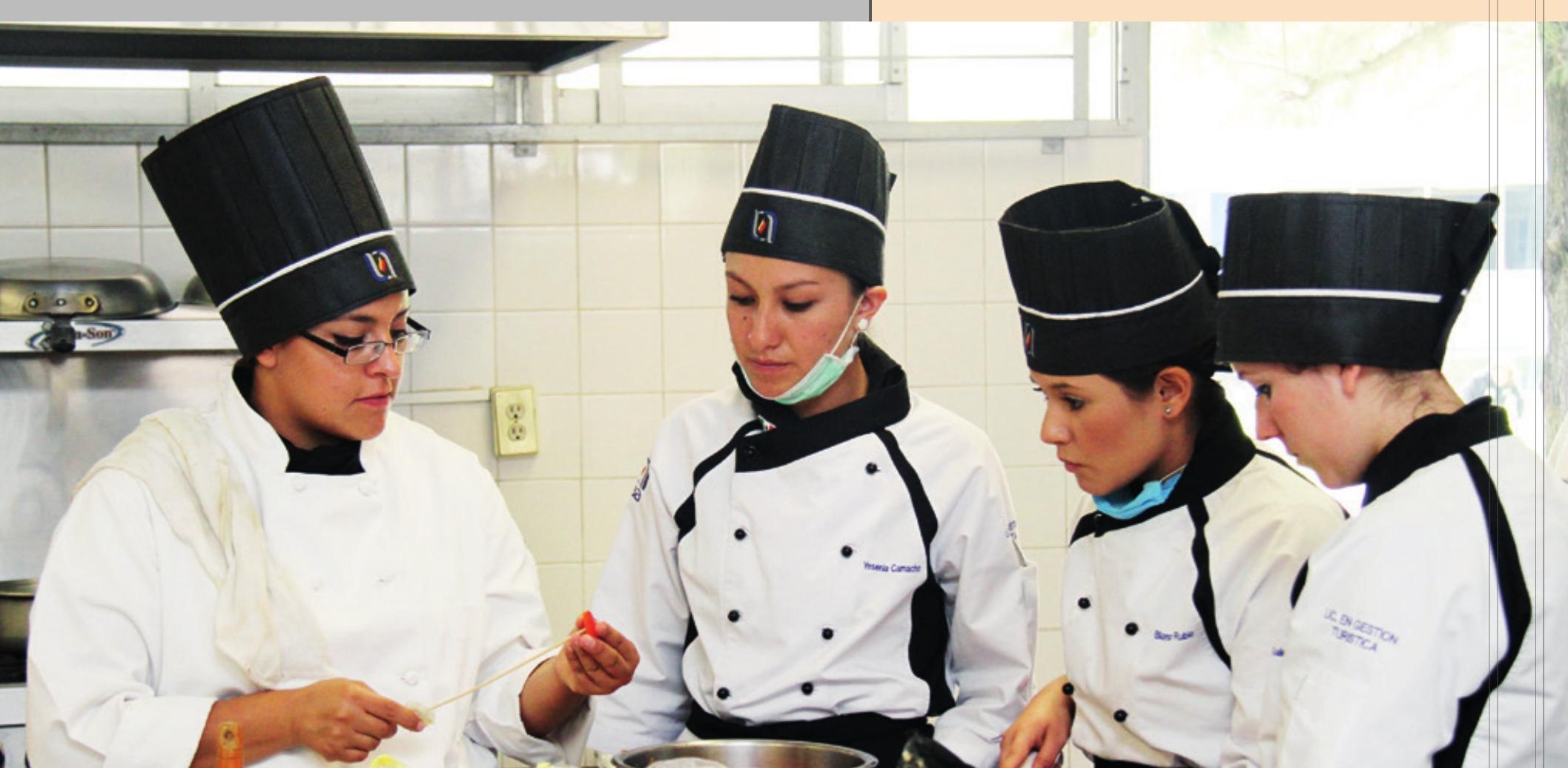

